\title{
Amantes náufragos en el mar de la corte: la visión antiáulica del amor en la obra de Cristóbal de Castillejo*
}

\author{
María del Rosario MARTíNEZ NAVARRO \\ Universidad de Sevilla \\ rosariomtnez@us.es
}

\begin{abstract}
RESUMEN
En la obra del salmantino Cristóbal de Castillejo aparece una importante reelaboración de la metáfora del «amante náufrago» dentro de la corriente del mare malorum y esta, a su vez, del subgénero de la sátira antiáulica, de la que el autor es uno de los máximos representantes. En este trabajo se aborda el tratamiento e inversión de este topos clásico, con el objetivo de denunciar y satirizar algunos de los vicios más escandalosos de la corte: la hipocresía, la falta de reconocimiento de los méritos personales o la mutabilidad de la misma. En sus escritos se desarrolla con agilidad y humor la doble metáfora del amor-mar, con la que se incluyen algunos de los motivos más recurrentes en la literatura anticortesana tales como la tormenta, el naufragio o la barca anegada, en relación con el antiguo tópico de la aegritudo amoris, como proyección de los numerosos males que sufren los cortesanos. A partir de esta asociación se denuncian, además, los riesgos y peligros de la aventura «amorosa» - entendida como tal la experiencia cortesana-, comparados a los de una improvisada y temeraria navegación, mediante una novedosa aportación y un giro de la famosa oposición corte / aldea.
\end{abstract}

Palabras clave: Amor, Castillejo, mare malorum, sátira antiáulica.

\begin{abstract}
The literary production of Cristóbal de Castillejo includes an important re-elaboration of the metaphor known as «the castaway lover» belonging to the mare malorum literary trend, which in turn, belongs to the anti-court satire subgenre, which the author from Salamanca mastered. This study analyzes the treatment and inversion of this classic topos as a way to denounce and satirize some of the most scandalous vices of the court, namely, its mutability, its hypocrisy, or the lack of recognition of personal merits. In his works, Castillejo

\footnotetext{
* El presente estudio forma parte de la Tesis Doctoral La literatura anticortesana en el Renacimiento español: Cristóbal de Castillejo, defendida en la Universidad de Sevilla (20 de junio de 2014) bajo la dirección del Dr. Rogelio Reyes Cano y calificada con Sobresaliente Cum Laude por unanimidad. Vaya desde aquí mi agradecimiento por sus constantes sugerencias.
} 
cunningly and comically develops the double metaphor love-sea which includes some of the most recurrent motifs of the anti-courtesan literature such as the storm, the shipwreck, or the flooded boat. These motifs are related to the ancient topic known as aegritudo amoris as a projection of the numerous ails affecting the members of the court. This association is used as the basis of his denunciation which likens the risks and perils of the love adventure to the court. These two issues are compared to an improvised and reckless navigation by means of an original contribution to the genre and a twist to the well-known opposition Court-Village. Keywords: Anti-Aulic Satire, Castillejo, love, mare malorum.

Castillejo, para quien, en palabras de M. D. Beccaria, «los caminos de la mar no le han sido ajenos», sigue en sus composiciones esa «tópica identificación de la corte con el mar y de la vida de los cortesanos con los riesgos de la navegación», pero la amplía «con la enumeración y descripción de los diferentes peligros que el navegar comporta» ${ }^{1}$. El poeta en algunos de sus escritos, a saber: el Sermón de amores, la Farsa de la Costanza, el Diálogo de mujeres, el Himno (de alabanza) a Nuestra Señora (Ave Maris Stella), la Glosa (del romance) de "Tiempo bueno», algunas letrillas amorosas, y en el Aula de cortesanos, su diálogo antiáulico más conseguido, entre otros, desarrolla con agilidad y a través de su particular humor la doble metáfora del amor-mar.

En concreto, dentro de sus «Obras de amores» ${ }^{2}$ se incluye en redondillas el romance tan glosado en la época de «Tiempo bueno» ${ }^{3}$. Sin alusión explícita a la corte, por la inclusión no casual del léxico del mar, aparte del mal de amores ${ }^{4}$, parece que los que tiene el autor son los originados por su miserable vida palaciega. De hecho, de esta composición destaca su «aire nostálgico y doliente» ${ }^{5}$, pues, tal vez, Castillejo añore no solo a una dama sino también su infancia al servicio del entonces infante Fernando de Habsburgo, al que le unía una estrecha amistad, frente a una etapa en la que puede que otros cortesanos recibieran sus favores y él cayera en el olvido. Se cierra cada estrofa de su creación con versos originales del romance (vv. 85-96):

\footnotetext{
${ }^{1}$ M. D. Beccaria (1997), p. 184.

${ }^{2}$ La denominación corresponde a la división temática tripartita («Obras de amores», «Obras de conversación y passatiempo» y «Obras morales y de devoción») de Juan López de Velasco en la editio princeps de las Obras de Castillejo de 1573.

${ }^{3}$ C. de Castillejo (2004), pp. 102-103, en nota. Los doce primeros versos del romance fueron glosados por Francisco Marquina hacia 1530. Véase C. de Castillejo (1958), p. 74, en nota. En el «Libro primero» de La Diana de Jorge de Montemayor también se incluye este romance. Véase J. de Montemayor (1996), pp. 28 y 329-330, en nota.

${ }^{4}$ Véase M. R. Martínez Navarro (2007).

${ }^{5}$ C. de Castillejo (2004), p. 102, en nota.
} 


\begin{abstract}
Qu'el mayor mal que ay aquí
es que sólo sé que peno;

y pues se tiene por bueno,

bien puedo decir asi:

Tiempo bienaventurado, en tiempo no conoscido, antes de tiempo perdido

y en todo tiempo llorado

yo navegaba por ti

con viento manso, sereno;

tiempo bueno, tiempo bueno,

¿quién te me apartó de mí?
\end{abstract}

El mismo caso se observa en las letrillas amorosas «Lo que quiero me es contrario» $\mathrm{y}$ «Por el travajo navego / sin le poder ver el fin» que glosa para relatar su mal de amores y, quizás, también su grave enfermedad cortesana, de la que no obtiene la recompensa esperada, en la que naufraga y de la que únicamente le librará la muerte, al ser incapaz de olvidar sus males:
De pura nezesidad
me es el morir nezesario,
y será más piedad, porque en esta enfermedad
lo que quiero me es contrario.
De nunca ver guarecido
es la causa muy notoria;
quantos médicos ha havido
me mandan tomar olvido;
yo siempre tomo memoria.
Este engaño y falsedad
todo ba en el boticario,
qu'es mi propia voluntad;
porque en esta enfermedad
lo que quiero me es contrario.

Resulta interesante el juego de palabras presente en el texto entre una de las virtudes teologales, la Esperanza, aludida aquí como la Tierra Prometida, y el viento que conduce hacia ella (bonanza), pero que, en realidad, hace naufragar al poeta en el peligroso golfo de la corte. Castillejo utiliza la imagen de la barca anegada y ruin, posiblemente en alusión velada a su señor:

\footnotetext{
${ }^{6}$ Para este y los demás textos aquí recogidos se ha seguido la edición de R. Reyes Cano de la Obra completa de Castillejo. Véase C. de Castillejo (1998).
} 


\begin{abstract}
A bien ninguno me allego que no salga al gallarín. Pensando hallar sosiego, por el travajo navego sin le poder ver el fin. Confiando en la bonanza, yo mismo me hize guerra; embárqueme en speranza, y en asomando la tierra, dentro del golfo me lanza. A cada paso me anego, por ser la barca tan ruin; que sperando surgir luego, por el travajo navego sin le poder ver el fin.
\end{abstract}

La composición recuerda al Soneto VII de Garcilaso de la Vega, con la alusión de las «mojadas ropas» y la tormenta en que se vio el amante, y sobre todo a la letrilla anónima de origen sefardí que entona el loco enamorado y también cortesano Cardenio en el capítulo XLIII de la primera parte del Quijote y que remiten, igualmente, a la metáfora del amante náufrago, inspirada directamente en Horacio (Odas, I, vv. 13-16) ${ }^{7}$, con la referencia de Palinuro, el «piloto de la flota de Eneas, que pereció al caer al mar» ${ }^{8}$. Algunos de los precedentes de la asociación mar-amor y de las imágenes del Cupido navigans y la navigatio Amoris ${ }^{9}$ lo constituyen diversas cantigas marineras, las obras de Bernat Metge ${ }^{10}$ y Ausiàs March, o La nao de amor de Juan de Dueñas ${ }^{11}$. El motivo se recoge también en La nao de amor del Comendador Escrivá; el Felixmarte de Hircania de Melchor de Ortega ${ }^{12}$; varios sonetos de Gutierre de Cetina ${ }^{13}$; una oda de Francisco de la Torre ${ }^{14}$; los versos de Fernando de Herrera $^{15}$; o en una canción de Luis de Camões ${ }^{16}$, entre otros ${ }^{17}$.

\footnotetext{
${ }^{7}$ Véase G. de la Vega (2001), p. 27, en nota.

${ }^{8}$ «-Marinero soy de amor, / y en su piélago profundo / navego sin esperanza / de llegar a puerto alguno. / Siguiendo voy a una estrella /que desde lejos descubro, / más bella y resplandeciente / que cuantas vió Palinuro. / Yo no sé adónde me guía / y, así, navego confuso, / el alma a mirarla atenta, / cuidadosa y con descuido». Véase M. de Cervantes (2001), p. 460.

${ }^{9}$ Véase G. de Cetina (2014), pp. 70-76.

${ }^{10}$ Véase B. Metge (2013).

${ }^{11}$ Véase N. Salvador Miguel (1977), p. 83; J. de Dueñas (1997); J. M. Blecua (1945), p. 22.

12 Véase R. Aguilar Perdomo (2001), pp. 9-27.

${ }^{13}$ Véase M. B. López (1981), pp. 275-277, en nota; J. M. Blecua (1945), p. 44; G. de Cetina (2014), pp. 511-522.

${ }^{14}$ Véase J. M. Blecua (1945), pp. 37-38.

${ }^{15}$ Véase M. B. López Bueno (1981), pp. 273-281.

${ }^{16}$ Véase E. Morales Blouin (1981), pp. 89-94.
} 
El amor como singladura sentimental o tempestad, la interacción amor-mar y la aventura amorosa a modo de arriesgada e improvisada navegación se aúnan en el Sermón de amores del salmantino. Incluso se podría entender en esta obra la asociación entre la mujer y la nave de otros textos de la lírica popular ${ }^{18}$. Con una temprana referencia a la metáfora del piloto ${ }^{19}$, dice así el Predicador (vv. 350-361, 2732-2741 y 2834-2838, respectivamente):

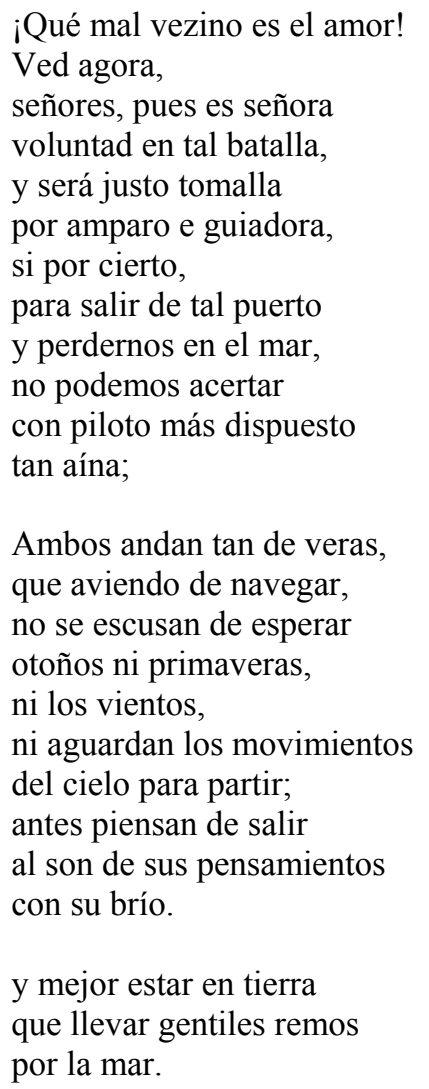

\footnotetext{
${ }^{17}$ Libro de Buen Amor (estrofas 650-651 b); Nao d'amores de Gil Vicente; Tragicomedia de don Duardos; soneto XXXIV de Garcilaso; soneto-prólogo de Acuña; Francisco de Medrano; Diego Hurtado de Mendoza; la barquilla de los cuatro romances piscatorios en La Dorotea (Acto III) de Lope de Vega. Véase M. B. López Bueno (1981); J. M. Blecua (1945); E. S. Morby (1952-1953), pp. 289-293.

${ }^{18}$ Véase J. M. Blecua (1945), p. 46; L. Fernández Guillermo (2001), p. 544.

${ }^{19}$ Presente asimismo, por ejemplo, en el Siervo libre de Amor de Juan Rodríguez del Padrón, en el Arte de marear de Antonio de Guevara, o en el Aviso de discretos (Segundo cancionero) de Montemayor.
} 
Mejor es no navegar

que ver la mar mansa y rasa.

Por otra parte, siguiendo la línea de poemas laudatorios a la figura de la Virgen María, tan frecuentes en la época, en el Himno (de alabanza) a Nuestra Señora (Ave Maris Stella), este último entre los textos «de devoción» de Castillejo ${ }^{20}$, el autor vuelve de nuevo a la metáfora de los vientos contrarios y al lenguaje de navegación con la vieja alusión a la estrella polar (el norte) como guía de los marineros o amantes devotos ${ }^{21}$ (de la Virgen, en este caso) para orientarse en su camino (vv. 1-8) 22 , pues «los mareantes no pueden tomar bien la barra sin la claridad del Sol, ò la de la Luna, ò de las Estrellas, porque siendo grande el fondo, pensando de ancorar, se pierden» $(A u t$.$) :$
Pues navegáis, alma mía, por el mar de pensamientos, do sois de contrarios vientos combatida cada día, para no temer fortuna mirad siempre aquella estrella del norte, porque sin ella no avréis bonança ninguna.

El Himno a Nuestra Señora y la Canción a Nuestra Señora, viniendo en la mar parecen recordar a la última canción del Canzoniere petrarquista, donde también, a modo de letanía, se invoca auxilio a la mujer trascendida en Virgen (stella). Para J. Montero, «esta aplicación de comparaciones entre la mujer y el amor con el mar engañoso e inestable y metáforas náuticas al tema amoroso constituyó un tópico

\footnotetext{
${ }^{20}$ Libre traducción del himno litúrgico latino homónimo atribuido a San Bernardo de Claraval, impulsor de la reforma cisterciense. Véase M. D. Beccaria (1997), p. 169.

${ }^{21}$ Castillejo en otras de sus «Obras de devoción», como la titulada La invención de la Cruz. $A$ instancia de una señora honesta y devota, sitúa igualmente su poema en estas mismas «coordenadas mixtas entre devoción religiosa y cortés». Véase M. D. Beccaria (1997), pp. 224-225.

${ }^{22}$ Esta idea similar de la Virgen como auxiliadora, guía de la nave y estrella del mar se encuentra en la composición De la mar eres estrella de Pero López de Ayala, en una Rogativa a la Virgen de Diego de Torres y Villarroel, o en la copla 26 de la Vida de Nuestra Señora de Antonio Hurtado de Mendoza, esta última recogida por el Diccionario de Autoridades (ver p. 654). Véase F. Blázquez (2006), pp. 14, 148-149, 190; respectivamente. En la colección no están recogidos estos poemas de temática marinera de Castillejo, de quien se transcribe tan solo un villancico.
} 
muy difundido y grato particularmente a los poetas petrarquistas» ${ }^{23}$, cuya base «reside en la comparación entre la mujer y el amor con el mar engañoso e inestable» y en la poesía cancioneril «derivó hacia las alegorías en torno a la nave de amor» ${ }^{24}$. La metáfora del puerto seguro como «libertad amorosa»es, por ello, «derivación» de esta analogía tópica entre el amor y una peligrosa travesía marítima ${ }^{25}$.

Precisamente en varias composiciones del italiano (XIV, XXVI, XLII, LXIII, LXXIII, LXXX, CXXXII, CLXXVII, CLXXXIX, CCVI, CCXXV, CCXXXIV, CCXXXV, CCLIII, CCLXIV y CCCXVII) se encuentran diversas referencias alegóricas al amor como tormenta turbulenta, al navegar tempestuoso por un mar horrible, de tristes olas y a la nave, barca o leño en la que el amante (navegante, marinero o piloto) naufraga y va a la deriva, a los escollos y dificultades de la navegación, al timón (gobierno) y al tranquilo puerto dentro de ese rico contexto amoroso. El mar, por tanto, en palabras de M. B. López, sería ese:

símbolo ad hoc para ser predicado de los avatares de próspera o adversa fortuna, que a su antojo conduce al hombre. [...] Como los sentimientos comunicados son las más veces adversos, el poeta, inexperto nauta, es conducido en su nave (imagen más simple por su funcionalidad en los pasajes líricos, pero enraizada en la tradición de la nao de amor) al arbitrio de las olas de mudanzas. Lo mismo que a la hora de la palinodia final el poeta suele defender su integridad moral por el engaño de que ha sido víctima, pues abandonó seguro puerto incitado por los favorables vientos de Favonio. [...] Es elemento perturbador, por servir de imaginario transmisor, en la mayoría de los casos, de estados de ánimos negativos ${ }^{26}$.

A este respecto, I. Macdonald apunta que

el reino de Neptuno, tan propenso a cambios fuertes e inesperados, a tempestades tremebundas y naufragios lastimosos, es figura apta para la pasión del amor, tan

${ }^{23}$ J. de Montemayor (1996), p. 220, en nota. En el Libro quinto de La Diana aparece este motivo: «-Discreta señora: como el navío anda perdido por la mar sin poder tomar puerto seguro, ansí anduvo mi pensamiento en los amores de Diana todo el tiempo que la quise bien; mas agora he llegado a un puerto donde plega a Dios que sea tan bien recebido como el amor que yo le tengo lo merece». Véase J. de Montemayor (1996), p. 220. Igualmente aparece en La Diana enamorada de Gaspar Gil Polo: «pasé en el mar de amor peligrosas agonías y tormentas, y ahora estoy gozando del seguro y sosegado puerto». Véase J. de Montemayor (1996), p. 422, en nota.

${ }^{24} \mathrm{~J}$. de Montemayor (1996), p. 422, en nota.

${ }^{25}$ J. de Montemayor (1996), p. 237, en nota. Sobre las imágenes del viaje por mar, véase M. P. Manero Sorolla (1990); E. R. Curtius (1999).

${ }^{26}$ M. B. López Bueno (1981), pp. 271-272. 
mudable, tan difícil de dominar, tan sujeto al naufragio del que se lanza en él, detrás de una pasión sin freno. ${ }^{27}$

Por consiguiente, Castillejo al referirse a la corte emplea la doble metáfora del amor-mar y representa con ella la falsedad de un lugar lleno de dificultades y contratiempos en el que el «amante» no tiene tampoco esa seguridad de llegar a buen puerto. El poeta amplía de esta manera la correspondencia $($ amor $=$ mar $=$ corte $)$, a partir de los motivos de la alegórica nave de amor y el viaje marítimo. Junto a estos dos motivos, se recurre al del mal amor, en estrecha relación con el de la nave de los locos. Por ello, en esta triple equivalencia amor $=$ mar $=$ corte tal vez esté también acudiendo a esa antigua idea presente en Virgilio (Bucólicas III, 101), Juan del Encina (Égloga de Plácida y Vitoriano) o Cervantes (Quijote, La Galatea), entre otros autores, como reflejo del «amor como enfermedad o desorden moral que destruye el estado de felicidad natural propio de la vida pastoril» ${ }^{28}$, en un novedoso giro de la oposición corte / aldea y con una aguda visión contemporánea y un análisis «psicologista» del sentimiento aplicado a la realidad cortesana.

El desprecio de la corte entendida como nefasto mar se manifiesta de igual forma en la Farsa de la Costanza del mirobrigense (vv. 2631-2642), siguiendo un «esquema compositivo propio de la "danza" de estados u oficios»". El motivo del aula como sepultura o muerte en vida tan recurrente en sus composiciones se expresa en los versos 2601-2642:

No ay negocio en esta vida,
de quantos podéis deçir,
que no le beais medir
con una misma medida
de cuydados.
Todos están aforrados
en soçobras semejantes;
preguntaldo a negociantes
en la corte sepultados
sin que mueran.
Aunque agan quanto quieran
y negocien a su gana,
del mesmo negoçio mana
con que contino se yeran
y fatiguen,

${ }^{27}$ I. MacDonald (1974), p. 217.

${ }^{28}$ J. de Montemayor (1996), p. 12, en nota, y p. 319, en nota.

${ }^{29}$ C. de Castillejo (2012), p. 200, en nota. 


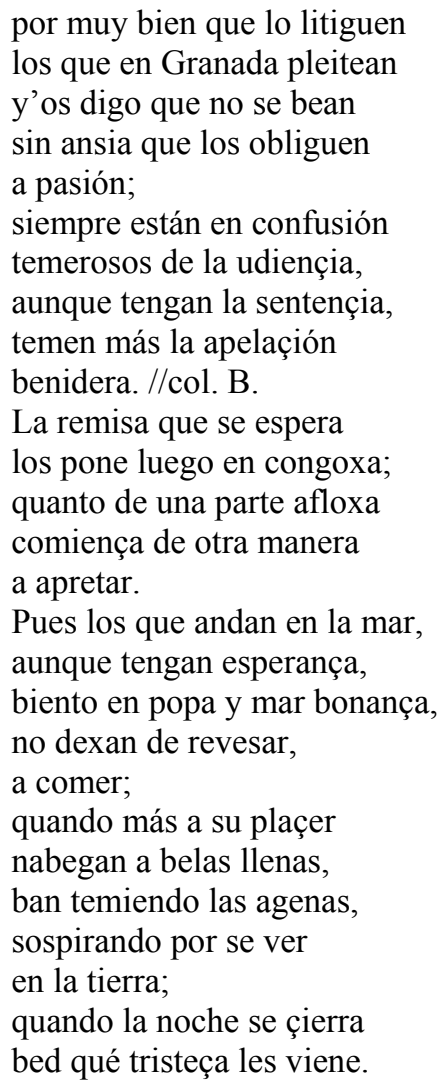

Finalmente, el tema tiene presencia en el extenso diálogo Aula de cortesanos, ya que desde los primeros versos de la composición queda constancia de que uno de los ejes temáticos es este de la corte aludida como un mar repleto de riesgos. A través del diálogo que entablan los personajes del joven Lucrecio y su tío, el experimentado Prudencio, sobre los pros y contras de la vida curial, Castillejo aborda el tratamiento del espacio áulico y lo describe como un mar tempestuoso donde naufragan los que habitan en él. Como a lo largo de los dos primeros capítulos el ingenuo aspirante a cortesano no termina de comprender los perjuicios que le puede acarrear la vida en el aula, su pariente prosigue una razonada exposición estableciendo la analogía metafórica entre esta y la navegación. Para Prudencio la corte es un piélago lleno de contratiempos, de desengaños y apariencias y así la describe para persuadir a su testarudo sobrino.

Por ejemplo, la violencia de los vientos del poder, la lisonja y la ambición descrita en el Aula se asemeja a los efectos producidos por el amor (nao de amores) en otros textos y, al igual que en el Canzoniere, su presencia pone en peligro el tópico del descanso reparador y anhelado. Son pocos los cortesanos que consiguen llegar a 
buen puerto y la mayoría, al reflejar en su propio ánimo la inestabilidad de la Fortuna, se vuelven hasta insomnes (vv. 768-775):

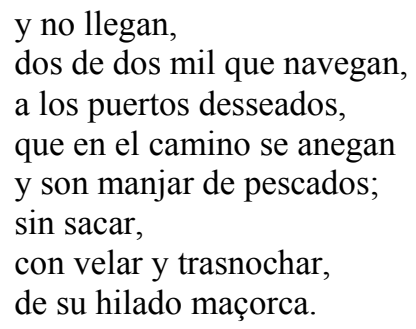

Castillejo en la Canción a Nuestra Señora, viniendo en la mar (v. 13), en el Diálogo de mujeres (v. 333) y en el verso 973 del Aula se refiere a la fusta o «buque de carga» (Aut.) rota y a la deriva; con ella traza un completo panorama de una corte donde reina esa misma locura de una nave mal gobernada que en un contexto amoroso es «combatida por las olas en la tormenta de la irracionalidad vital y amorosa» ${ }^{30}$ y que ahora es, de la misma forma, presa de la furia de voraces olas en las que los inquilinos, «al navegar agua arriba / sin favor» (vv. 3057-3058), deben saber navegar «con buen norte» (v. 636) para sobrevivir, sin esperar, por el contrario, a que nadie les venga a rescatar (vv. 2180-2185):
Pero ya
qu'en la corte donde está
no decline a los estremos
y navegue por do va
con buenas velas y remos, governando.

Lucrecio, al igual que hace Alethio en el Diálogo de mujeres (v. 579) ${ }^{31}$, recurre también a la construcción «dar de través» o «dar al través» (v. 86), adverbio de origen náutico que significa «lo mismo que dar al traste» $(A u t .)^{32}$. Lo desarrollan los versos 75-89:
Mas primero, según haze el marinero quando sale de arrancada, es de ver adónde quiero

\footnotetext{
${ }^{30}$ A. Cortijo (2007), p. 141.

${ }^{31}$ «Sin culpa de las mugeres / muy pocos dan de través / no forçados». Véase C. de Castillejo (1986), p. 84.

32 Véase C. de Castillejo (1986), p. 84, en nota, y p. 137, en nota.
} 


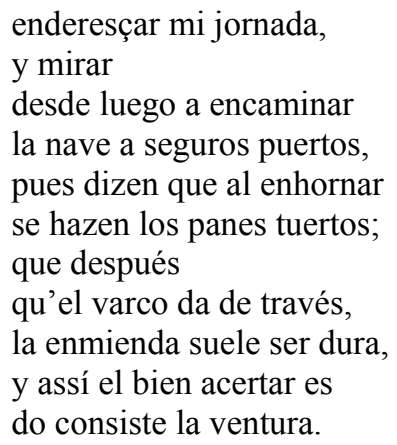

Tras lo expuesto, podemos afirmar que Castillejo supo mostrar genialmente las dobleces de lo áulico, evidenciando la otra cara de la moneda, el haz y el envés del mundo de la corte. El poeta desvela su otra faz: la del día a día, la que se percibía realmente en las aulas y que saca a la luz cuestiones relativas a las experiencias negativas y a los percances que comparten los que pertenecen a ella. En la mayoría de sus textos late la vieja metáfora del mare malorum y con ella un variado campo léxico-semántico del arte de navegar que reutiliza con habilidad la terminología de los tratados de navegación renacentistas. El leitmotiv de la corte como mar seguirá su fructífero rumbo en el siglo XVII y posteriores.

El punto de partida de los textos anticortesanos de Castillejo, en patente simetría con sus fuentes y textos contemporáneos, es esa «metáfora continuada que identifica la corte como un mare malorum en el que el navegar es dificilísimo» ${ }^{33}$. En ellos, de forma similar, se lleva a cabo una imitación amplificada y una readaptación del eje temático, así como de vocablos selectos pertenecientes al léxico de marinería, en consonancia con la tratadística del momento y con amplias muestras de «un manejo extraordinario de la lengua y de un vocabulario riquísimo $\rangle^{34}$.

A modo de nexo en clave, los testimonios tejen solidariamente una realidad de adversidades y decepciones, subyaciendo en ellos una moraleja común con un práctico mensaje concienciador para que nunca nos lancemos a navegación tan azarosa, tan funesta como esta de la corte ${ }^{35}$. Guevara en su Arte de marear recuerda que ya lo advertía Publiano, el filósofo: «Improbe Neptunum accusat qui iterum naufragium facit. Como si dijese: "Injustamente de la mar se queja el que dos veces osa pasarla"» ${ }^{36}$. Ningún loco osaría, pues, a repetir.

\footnotetext{
${ }^{33}$ B. Periñán (1984), p. 269.

${ }^{34}$ M. D. Beccaria (1997), p. 500, en nota.

35 «Ne unquam navigationi te committas tam periculosae, tam exitiosae». Véase U. von Hutten (1518), f. 14r, 27-28.

${ }^{36}$ «Carta del autor, enviada al ilustre señor don Francisco de los Cobos». Véase A. de Guevara (1987), p. 294.
} 


\section{OBRAS CITADAS}

Aguilar Perdomo, Rosario: «La nao de amor del Felixmarte de Hircania y otras composiciones líricas en los libros de caballerías penisulares», Revista de literatura medieval, 13.2 (2001), pp. 9-27.

Aut. $=$ ReAl ACADEMIA EsPaÑola: Diccionario de Autoridades, Madrid, Gredos, 1990.

BeCCARIa Lago, María Dolores: Vida y obra de Cristóbal de Castillejo, Madrid, Real Academia Española, 1997.

BLÁzQueZ, Feliciano: Santa María la Virgen, Antología de poesía mariana en lengua castellana, Madrid, Biblioteca de Autores Cristianos, 2006.

BLECUA TEIJEIRO, José Manuel: El mar en la poesía española: selección y carta de navegar, Madrid, Editorial Hispánica, 1945.

CASTILlEJo, Cristóbal de: Obras II, Madrid, Espasa-Calpe, 1958.

: Diálogo de mujeres, Madrid, Castalia, 1986.

: Obra completa, Madrid, Biblioteca Castro, 1998.

: Antología poética, Madrid, Cátedra, 2004.

: Farsa de la Costanza, Madrid, Cátedra, 2012.

Cervantes SaAVedra, Miguel de: Don Quijote de la Mancha, Barcelona, Planeta, 2001.

CetinA, Gutierre de: Rimas, Madrid, Cátedra, 2014.

CORTIJo OCAÑA, Antonio: «El Siervo libre de amor y Petrarca: a propósito del motivo de la nave», Revista de poética medieval, 18 (2007), pp. 133-154.

CURTIUS, Ernst Robert: Literatura europea y Edad Media latina, México, Fondo de Cultura Económica, 1999.

DUEÑAS, Juan de: La nao de amor. Misa de amores, Viareggio - Lucca, Mauro Baroni, 1997.

FERNÁNDEZ GUILLERMO, Leonor: «El mar y el barco como símbolos en la antigua lírica popular española», en Lyra mínima oral (los géneros breves de la literatura tradicional). Actas del Congreso Internacional celebrado en la Universidad de Alcalá (Alcalá de Henares, 28-30 de octubre de 1998), Alcalá de Henares, Universidad de Alcalá, 2001, pp. 541-548.

GuEVARA, Antonio de: Menosprecio de corte y alabanza de aldea; Arte de marear, Madrid, Cátedra, 1987.

HutTen, Ulrich von: Vlrichi De Hvtten Eqvitis Germani. Avla. Dialogvs, Augsburg, Grimm \& Vuyrsung, 1518.

LÓPEZ BUENO, María Begoña: «La oposición Ríos/Mar en la imaginería del petrarquismo y sus implicaciones simbólicas: de Garcilaso a Herrera», Analecta Malacitana: Revista de la Sección de Filología de la Facultad de Filosofía y Letras, 4.2 (1981), pp. 271-272.

MACDONALD, Inés: «La égloga II de Garcilaso», en La poesía de Garcilaso. Ensayos críticos, Barcelona, Ariel, 1974. 
MANERo SOROLla, María Pilar: Imágenes petrarquistas en la lírica española del Renacimiento. Repertorio, Barcelona, PPU, 1990.

MARTíNEZ NAVARRO, María del Rosario: «De amor y otros males en la obra de Cristóbal de Castillejo», en Medicina y Literatura VI. Actas del VI Simposio Interdisciplinar de Medicina y Literatura (Real Colegio Oficial de Médicos de la Provincia de Sevilla, 4, 5 y 6 de abril de 2006), Sevilla, Padilla Libros Editores y Libreros, 2007, pp. 243-251.

MeTGE, Bernat: The Book of Fortune and Prudence, Amsterdam, John Benjamins, 2013.

MONTEMAYOR, Jorge de: La Diana, Barcelona, Crítica, 1996.

Morales Blouin, Egla: El ciervo y la fuente: Mito y Folklore del Agua en la Lírica Tradicional, Madrid, Porrúa, 1981.

MORBY, Edwin S.: «A Footnote on Lope de Vega's barquillas», Romance Philology, VI (1952-1953), pp. 289-293.

PERIÑÁN MATEOS, Blanca: «Un caso de imitación compuesta: el Aula de Cortesanos», Crotalón. Anuario de Filología española, I (1984), pp. 255-281.

SAlVAdOR Miguel, Nicasio: La poesía cancioneril. El «Cancionero de Estúñiga», Madrid, Alhambra, 1977.

VEGA, Garcilaso de la: Obra poética y textos en prosa, Barcelona, Crítica, 2001. 